\title{
The relationship between the molecular structure of natural acetogenins and their inhibitory activities which affect DNA polymerase, DNA topoisomerase and human cancer cell growth (Review)
}

\author{
YUKI MATSUI $^{1}$, TOSHIFUMI TAKEUCHI ${ }^{3}$, YUKO KUMAMOTO-YONEZAWA ${ }^{1}$, MASAHARU TAKEMURA ${ }^{4}$, \\ FUMIO SUGAWARA $^{3}$, HIROMI YOSHIDA ${ }^{1,2}$ and YOSHIYUKI MIZUSHINA ${ }^{1,2}$ \\ ${ }^{1}$ Laboratory of Food and Nutritional Sciences, Department of Nutritional Science, and ${ }^{2}$ Cooperative Research Center of \\ Life Sciences, Kobe-Gakuin University, Nishi-ku, Kobe, Hyogo 651-2180; ${ }^{3}$ Department of Applied Biological \\ Science, Tokyo University of Science, Yamazaki, Noda, Chiba 278-8510; ${ }^{4}$ Faculty of Science, \\ Tokyo University of Science, Kagurazaka, Shinjuku-Ku, Tokyo 162-8601, Japan
}

Received February 18, 2009; Accepted March 3, 2009

DOI: 10.3892/etm_00000004

\begin{abstract}
Acetogenins from the Annonaceous plant are a fatty acid-derived natural product. Chemically synthesized natural acetogenins, such as mucocin (compound 1), jimenezin (compound 2), muconin (compound 4), pyranicin (compound 5) and pyragonicin (compound 6) were investigated. Concomitantly, 19-epi jimenezin (compound 3), 10-epi pyragonicin (compound 7) and a $\gamma$-lactone (compound 8), which is estimated to be a biosynthetic precursor of acetogenins, were synthesized and investigated. Compounds 5 and 6 strongly inhibited, and compound 7 moderately inhibited the activities of mammalian DNA polymerases (pols), such as replicative pol $\alpha$ and repair/recombination-related pol $\beta$ and $\lambda$, and also inhibited human DNA topoisomerase (topos) I and II activities. On the other hand, compounds 1-4 and 8 did not influence the activities of any pols and topos. Compound 5 was the strongest inhibitor of the pols and topos tested, and the $\mathrm{IC}_{50}$ values were 5.0-9.6 $\mu \mathrm{M}$, respectively. These compounds also suppressed human cancer cell growth with
\end{abstract}

Correspondence to: Dr Yoshiyuki Mizushina, Laboratory of Food and Nutritional Sciences, Department of Nutritional Science, KobeGakuin University, Nishi-ku, Kobe, Hyogo 651-2180, Japan

E-mail: mizushin@nutr.kobegakuin.ac.jp

Abbreviations: pol, DNA-directed DNA polymerase (EC 2.7.7.7); topo, DNA topoisomerase; THF, tetrahydrofuran; THP, tetrahydropyran; TdT, terminal deoxynucleotidyl transferase; $\mathrm{IC}_{50}, 50 \%$ inhibitory concentration; dTTP, 2'-deoxythymidine 5'-triphosphate; dNTP, 2'-deoxyribonucleotide 5'-triphosphate; $\mathrm{LD}_{50}, 50 \%$ lethal dose

Key words: acetogenins, pyranicin, enzyme inhibitor, DNA polymerase, DNA topoisomerase, cell cycle arrest, apoptosis, anti-cancer agent, computer simulation almost the same tendency as the inhibition of pols and topos. Compound 5 was the strongest suppressor of the proliferation of the promyelocytic leukemia cell line, HL-60, in human cancer cell lines tested with an $\mathrm{LD}_{50}$ value of $9.4 \mu \mathrm{M}$, and arrested the cells at G1 phases, indicating that it blocks DNA replication by inhibiting the activity of pols rather than topos. This compound also induced cell apoptosis. The relationship between the three-dimensional molecular structure of acetogenins and these inhibitory activities is discussed. The results suggested that compound 5 is a lead compound of potentially useful cancer chemotherapy agents.

\section{Contents}

1. Introduction

2. Effects of acetogenins on mammalian DNA polymerases $\alpha, \beta$ and $\lambda$

3. Effects of acetogenins on human DNA topoisomerases I and II

4. Effects of acetogenins on human cancer cell line, HL-60

5. Three-dimensional structures of acetogenins

6. Effects of compounds 5 on DNA metabolic enzymes

7. Effects of compound 5 on cultured human cancer cells

8. Effects of the influence on HL-60 cells by compound 5

9. Discussion

10. Conclusion

\section{Introduction}

Acetogenins are a class of potent bioactive compounds in various plant species in the Annonaceae family (1). These acetogenins are a relatively new class of fatty acid-derived natural products that have a wide range of biological activities, such as cytotoxic, antitumor and immunosuppressive effects (1-3). They are characterized by the presence of one to three 
tetrahydrofuran (THF) rings in the center of a long alkyl chain with a butenolide moiety at the end. Besides such classical types, acetogenins with a tetrahydropyran (THP) ring in the long chain, such as mucocin (compound 1), jimenezin (compound 2), muconin (compound 4), pyranicin (compound 5) and pyragonicin (compound 6) have also been discovered (Fig. 1) (4-7).

DNA polymerase (pol) catalyzes the addition of deoxyribonucleotides to the 3'-hydroxyl terminus of primed double-stranded DNA molecules (8). The human genome encodes at least 15 pols to conduct cellular DNA synthesis $(9,10)$. Eukaryotic cells contain three replicative pols $(\alpha, \delta$ and $\varepsilon)$, mitochondrial pol $\gamma$ and at least twelve non-replicative pols $[\beta, \zeta, \eta, \theta, \mathrm{\iota}, \kappa, \lambda, \mu, v$, terminal deoxynucleotidyl transferase (TdT) and REV1] (9-11).

DNA topoisomerases (topos) are key enzymes that control the topological state of DNA. Type I enzymes act by transiently nicking one of the two DNA strands. Type II enzymes nick both DNA strands which are ATP-dependent and are involved in many vital cellular processes that influence DNA replication, transcription, recombination, integration and chromosomal segregation (12).

DNA metabolic enzymes, such as pols and topos, are not only essential for DNA replication, repair and recombination, but are also involved in cell division. Selective inhibitors of these enzymes are considered as a group of potentially useful anti-cancer and anti-parasitic agents, because some inhibitors suppress human cancer cell proliferation and have cytotoxicity (13-16).

Non-classical THP acetogenins have become interesting compounds because of their powerful antitumor activity; thus, total synthesis of the natural and non-natural acetogenins (compounds 1-8 of Fig. 1) was achieved (17-25). Since McLaughlin et al and Mata et al reported that some acetogenins have cytotoxicity against human cancer cell lines (4-7), the purpose of this review is to investigate the biochemical action of the compounds against DNA metabolic enzymes such as pols and topos, and to use the compound as an antineoplastic agent.

Therefore, we describe the inhibitory activities of chemically synthesized acetogenins against pols, topos and other DNA metabolic enzymes, as well as cellular proliferation processes such as DNA replication of human cancer cells. The analysis of the relationship between the essential molecular structure and bioactive function of acetogenins shows that acetogenins are an ideal model for the development of new anti-cancer drugs.

\section{Effects of acetogenins on mammalian DNA polymerases $\alpha, \beta$ and $\lambda$}

The structures of the acetogenins (compounds 1-8), which were chemically synthesized, are shown in Fig. 1. The inhibitory activity of mammalian pols, such as calf pol $\alpha$, rat pol $\beta$ and human pol $\lambda$, against $10 \mu \mathrm{M}$ of each compound was investi-gated. For pols, poly $(\mathrm{dA}) / \operatorname{oligo}(\mathrm{dT})_{12 \cdot 18}(\mathrm{~A} / \mathrm{T}=2 / 1)$ and 2'-deoxythymidine 5'-triphosphate (dTTP) were used as the DNA template-primer and nucleotide (i.e., 2'-deoxyribonucleotide 5'-triphosphates, dNTP) substrate, respectively. One unit of pol activity was defined as the amount of enzyme
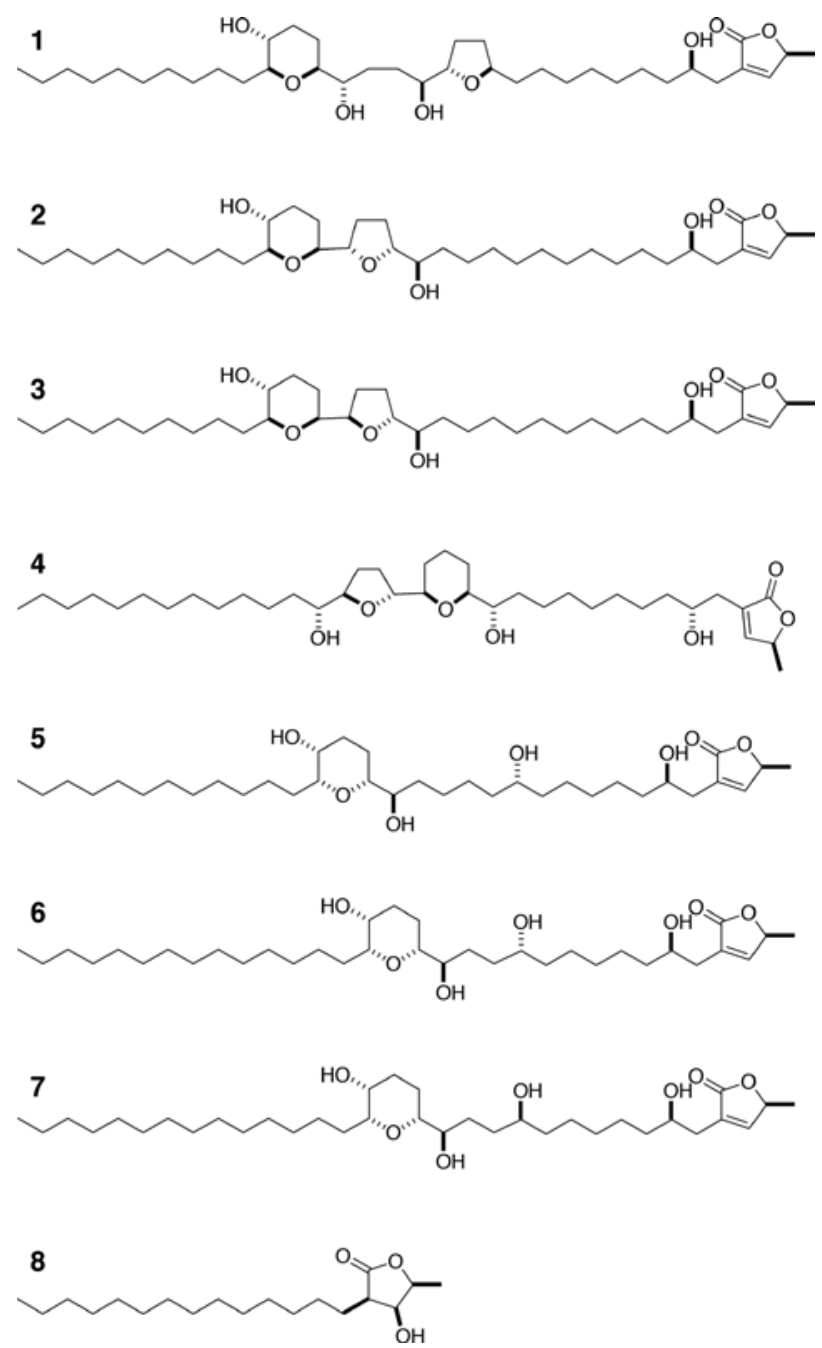

Figure 1. Chemical structures of acetogenins. Compound 1, mucocin; compound 2, jimenezin; compound 3, 19-epi jimenezin; compound 4, muconin; compound 5, pyranicin; compound 6 , pyragonicin; compound 7 , 10-epi pyragonicin and compound 8, 3-hydroxy-4-methyl-2-tetradecyl-4butanolide.

that catalyzed the incorporation of $1 \mathrm{nmol}$ dNTP (i.e., dTTP) into synthetic DNA template-primers in $60 \mathrm{~min}$ at $37^{\circ} \mathrm{C}$ under the normal reaction conditions for each enzyme $(26,27)$. Pol $\alpha$ and pols $\beta$ and $\lambda$ were used as representative replicative and repair/recombination-related pols, respectively (8-10).

As shown in Fig. 2A, compounds 5 and 6 significantly inhibited the activities of these pols, while compound 8 had no effect. Compound 5 showed the strongest inhibition of pol $\alpha$, $\beta$ and $\lambda$ activities in the tested compounds, and $50 \%$ inhibition was observed at doses of 5.3, 9.6 and $2.3 \mu \mathrm{M}$, respectively. When activated DNA (i.e., DNA digested by bovine deoxyribonuclease I) was used as the DNA template-primer instead of poly $(\mathrm{dA}) / \mathrm{oligo}(\mathrm{dT})_{12-18}(\mathrm{~A} / \mathrm{T}=2 / 1)$, the mode of inhibition of these compounds did not change (data not shown).

\section{Effects of acetogenins on human DNA topoisomerases I and II}

Topo inhibitory activity of acetogenins was then investigated. The relaxation activity of topos I and II from humans was determined by detecting the conversion of supercoiled plasmid 
A

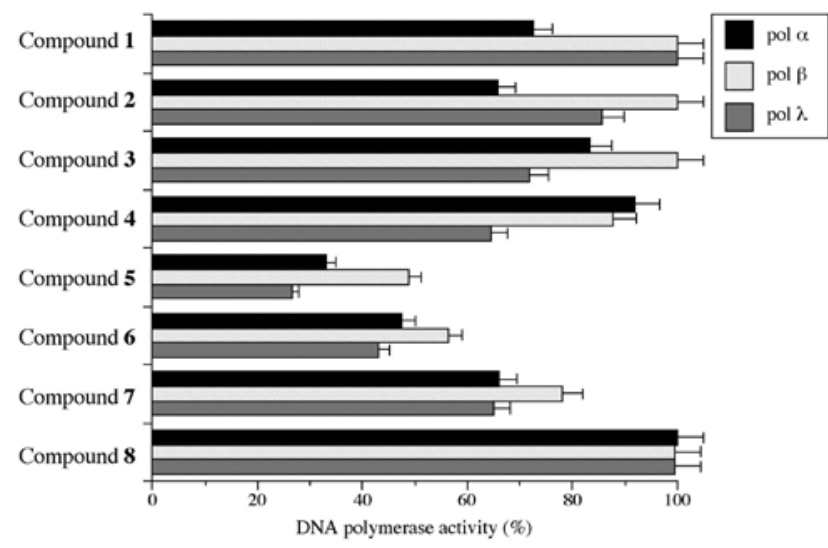

C

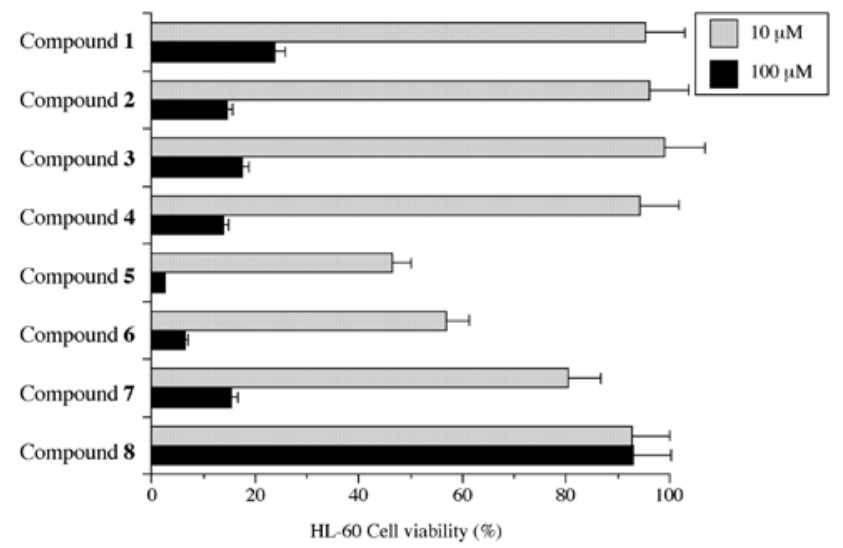

DNA to its relaxed form (28). Compounds 5-7 $(10 \mu \mathrm{M})$, respectively, inhibited the activities of topos dose-dependently, while the other compounds did not (Fig. 2B). In human topos I and II, compound 5 showed the strongest inhibition of the tested compounds. Topo I and II inhibitors, camptothecin and etoposide, inhibited the relaxation activities of topos I and II with $\mathrm{IC}_{5_{0}}$ values of 85 and $70 \mu \mathrm{M}$, respectively (28). Therefore, compound 5 was a stronger inhibitor of topos I and II than camptothecin and etoposide, respectively.

These results suggested that the inhibitory activity of acetogenins between mammalian pols and human topos had the same tendency, and the inhibitory effect on pols was almost as strong as that on topos. Thus, the mechanism of the inhibitory effect of acetogenins, including compound 5, on cultured human cancer cells was investigated.

\section{Effects of acetogenins on human cancer cell line, HL-60}

Pols and topos have recently emerged as important cellular targets for chemical intervention in the development of anti-cancer agents. Acetogenins therefore are useful in chemotherapy, and the cytotoxic effect of eight compounds against the human promyelocytic leukemia cell line HL-60, derived from a cancer patient, was investigated. The survival rate of cultured human cancer cells was determined by MTT (3-(4,5dimethylthiazol-2-yl)-2,5-diphenyl tetrazolium bromide) assay (29).
B

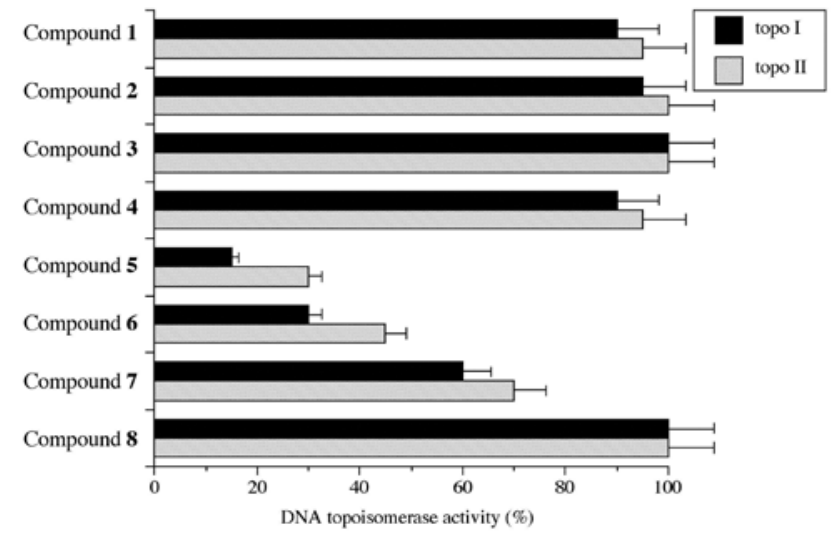

Figure 2. Effect of acetogenins on the activities of mammalian pols, human topos and human cancer cell growth. (A) Each compound $(10 \mu \mathrm{M})$ was incubated with calf pol $\alpha$, rat pol $\beta$ and human pol $\lambda$ ( 0.05 units each). Pol activity in the absence of the compound was taken as $100 \%$. Data are shown as the mean \pm SEM of three independent experiments. (B) Each compound $(10 \mu \mathrm{M})$ was incubated with human topos I and II. Topo activity in the absence of the compound was taken as $100 \%$. Data are shown as the mean \pm SEM of three independent experiments. (C) Each compound (10 and $100 \mu \mathrm{M})$ was added to the culture of the promyelocytic leukemia cell line HL-60, and incubated for $24 \mathrm{~h}$. The rate of viability was determined by MTT assay (29). Cell viability of the cancer cells in the absence of the compound was taken as $100 \%$. Data are shown as the mean \pm SEM of five independent experiments.

As shown in Fig. 2C, $10 \mu \mathrm{M}$ of compound 5 had the strongest growth inhibitory effect on HL-60, while compounds 6 and 7 had the second and third strongest, respectively. At a concentration of $100 \mu \mathrm{M}$, compounds 1-7 strongly suppressed cancer cell growth, while compound 8 had no influence (i.e., in order of cytotoxicity observed at a concentration of $10 \mu \mathrm{M}$ : compound $5>$ compound $6>$ compound $7>$ compound $1=$ compound $2=$ compound $3=$ compound $4>$ compound 8 ). The suppression of cell growth had almost the same tendency as the inhibition of mammalian pols and human topos among the 8 compounds (Fig. 2A and B, respectively), suggesting that the cause of cancer cell influence involves the activities of pols, including replicative and repair/recombination pols, as well as topos.

\section{Three-dimensional structures of acetogenins}

To obtain more information about the molecular basis for differential inhibition spectra exhibited by the acetogenins prepared, computational analyses of compounds 1-8 were performed (Fig. 3). Acetogenin models were simulated with force-field parameters based on the Consistent Valence Force Field. Temperature was set at $298 \mathrm{~K}$. Calculations based on simulation images were carried out using Insight II (Accelrys Inc., San Diego, CA, USA). Electrostatic potentials on the surface of compounds were analyzed by WebLab ViewerLite software (version 3.2; Accelrys Inc.). 
A

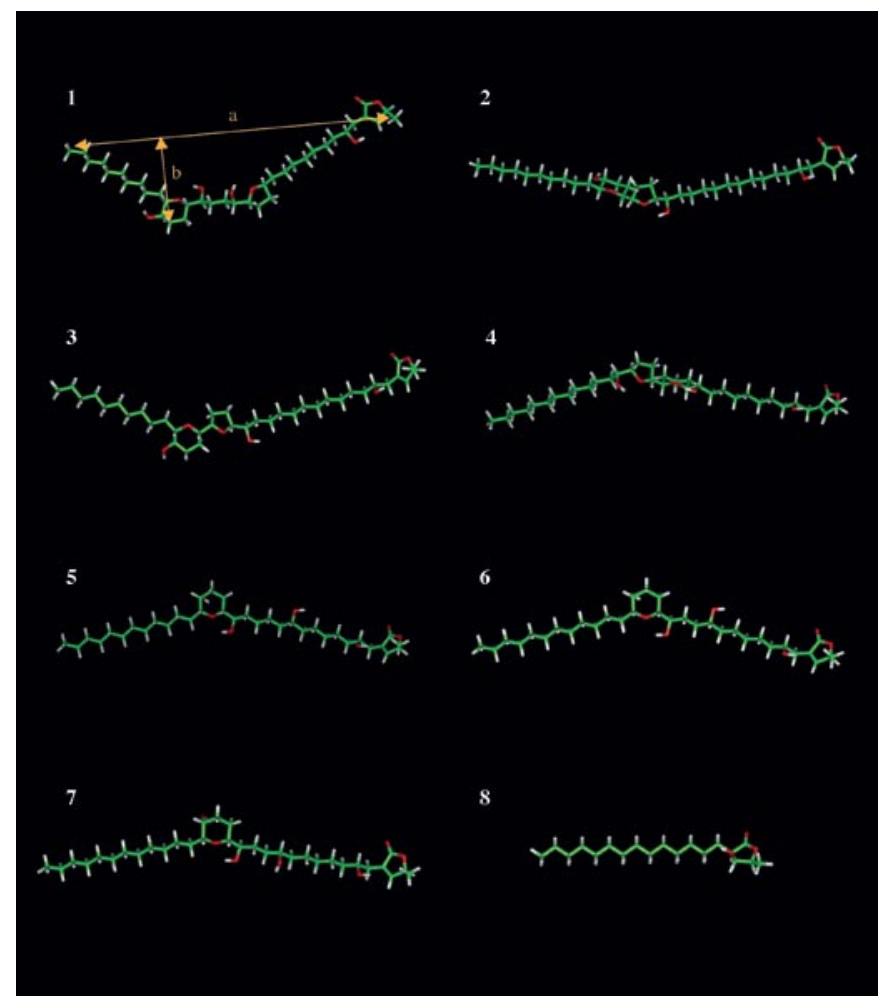

B

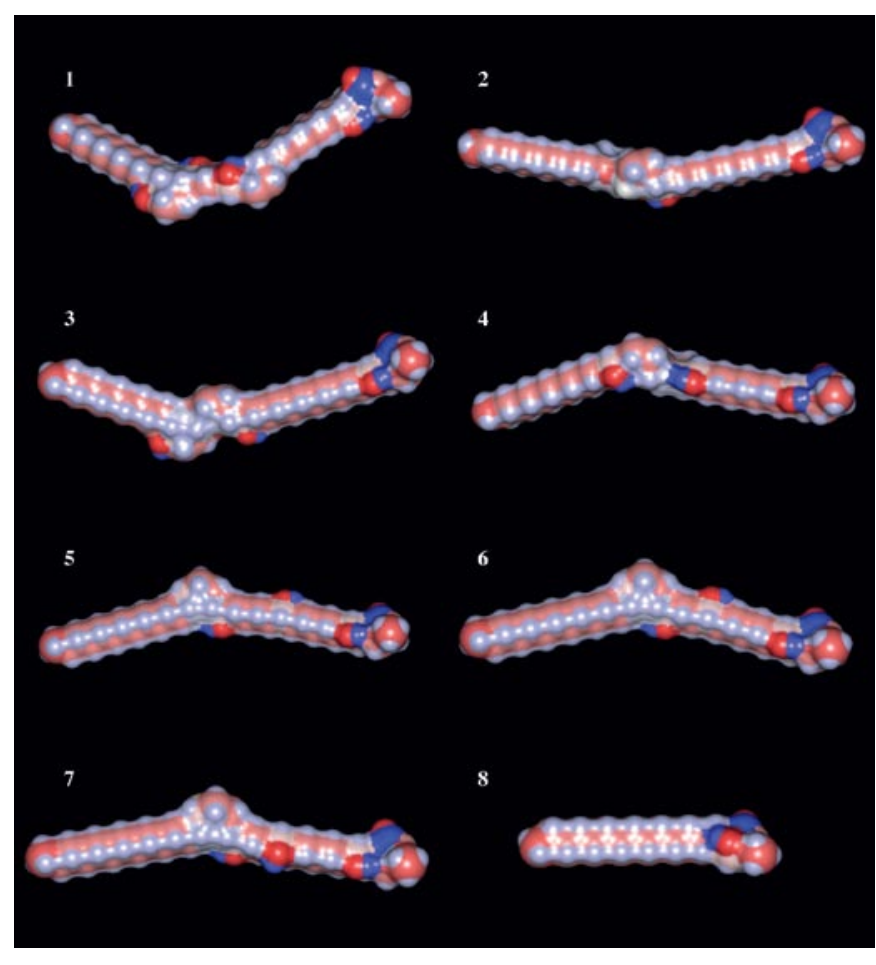

Figure 3. Computer graphics of acetogenins. (A) Stick models of compounds 1-8. Carbons, oxygens and hydrogens of the compounds are indicated in green, red and white, respectively. Stick models of acetogenins were built using the graphics program Insight II (Accelrys Inc.). (B) Electrostatic potentials on molecular surfaces of compounds 1-8. Blue areas are positively charged, red are negatively charged, and white are neutral. Electrostatic potentials on molecular surfaces of acetogenins were analyzed using WebLab ViewerLite software (version 3.2; Accelrys Inc.).

Fig. 3A shows the front view of the three-dimensional structures, from which were calculated energy-minimized compounds. The molecular length ' $a$ ' and width ' $b$ ' of the three-dimensional structure of the compounds based on Fig. 3A are indicated in Table I. Compounds tested as acetogenins have a butenolide or $\gamma$-lactone moiety at the end. Compounds 1-7 also consist of one or two rings, such as THF and/or THP, in the center, but compound 8 has no other rings. Since compound 8 did not influence the activities of pols, topos and HL-60 cell growth, the moiety of THF and/or THP rings of compounds 1-7 may be important for the inhibition of mammalian pols, human topos and human cancer cell growth. The molecular length of compounds 1-7 was $\sim 1$.9-fold longer than that of compound 8 (i.e., 33.63-37.76 $\AA$ and $19.80 \AA$, respectively). Moreover, the molecular length (33-38 $\AA$ ) of the compound is essential for these inhibitory activities. Compounds 5-7 contain a THP ring in the center of the structure, and the moiety has a slightly V-type shape. Compounds 1-4 also have this V-type shape. The width of compounds 5-7 is less than that of compounds 1,3 and 4 , but is larger than that of compound 2 (Table I). These results suggested that the width of the three-dimensional structure of compounds 5-7 (i.e., 5.43-5.94 $\AA$ ) is important for pols, topos and cancer cell growth inhibition.

Fig. 3B indicates that a comparison of the electrostatic potential surfaces of the acetogenins revealed a difference in their overall disposition and affinity. The electrostatic potential at each point on a constant electronic density surface
Table I. Molecular length and width of three-dimensional structure of compounds 1-8.

\begin{tabular}{lcc}
\hline Compound & Length $(\AA)$ & Width $(\AA)$ \\
\hline 1 & 33.63 & 8.65 \\
2 & 37.76 & 5.11 \\
3 & 36.96 & 7.49 \\
4 & 37.13 & 6.24 \\
5 & 37.03 & 5.94 \\
6 & 34.40 & 5.55 \\
7 & 34.80 & 5.43 \\
8 & 19.80 & 5.43 \\
\hline
\end{tabular}

Energy-minimized three-dimensional compounds 1-8 were prepared using Insight II (Accelrys). The length and width of the molecular structure are indicated as 'a' and 'b', respectively in Fig. 3A.

(approximating the van der Waals surface for each arrangement) is represented graphically, with red corresponding to regions where the electrostatic potential is most negative, and blue corresponding to the most positive regions. As shown in Fig. 3B, compounds 5-7 have four hydroxyl groups, and compound 5 has the same three-dimensional position of these groups as compound 6, supporting the enhancement of the negative and positive electrostatic potential on $\mathrm{O}$ and $\mathrm{H}$ atoms 
Table II. $\mathrm{IC}_{50}$ values of compound 5 on the activities of various DNA polymerases and other DNA metabolic enzymes.

\begin{tabular}{|c|c|}
\hline Enzyme & $\begin{array}{c}\mathrm{IC}_{50} \text { value } \\
(\mu \mathrm{M})\end{array}$ \\
\hline \multicolumn{2}{|l|}{ Mammalian DNA polymerases } \\
\hline Calf DNA polymerase $\alpha$ & $5.3 \pm 0.4$ \\
\hline Rat DNA polymerase $\beta$ & $9.6 \pm 0.8$ \\
\hline Human DNA polymerase $\gamma$ & $5.9 \pm 0.4$ \\
\hline Human DNA polymerase $\delta$ & $8.4 \pm 0.7$ \\
\hline Human DNA polymerase $\varepsilon$ & $15.8 \pm 1.4$ \\
\hline Human DNA polymerase $\eta$ & $10.2 \pm 0.9$ \\
\hline Human DNA polymerase ı & $13.0 \pm 1.2$ \\
\hline Human DNA polymerase $\kappa$ & $11.1 \pm 1.0$ \\
\hline Human DNA polymerase $\lambda$ & $2.3 \pm 0.2$ \\
\hline Calf terminal deoxynucleotidyl transferase & $6.3 \pm 0.5$ \\
\hline \multicolumn{2}{|l|}{ Fish DNA polymerases } \\
\hline Cherry salmon DNA polymerase $\delta$ & $8.8 \pm 0.7$ \\
\hline \multicolumn{2}{|l|}{ Insect DNA polymerases } \\
\hline Fruit fly DNA polymerase $\alpha$ & $6.5 \pm 0.5$ \\
\hline Fruit fly DNA polymerase $\delta$ & $8.9 \pm 0.8$ \\
\hline Fruit fly DNA polymerase $\varepsilon$ & $14.0 \pm 1.3$ \\
\hline \multicolumn{2}{|l|}{ Plant DNA polymerases } \\
\hline Cauliflower DNA polymerase I ( $\alpha$-like) & $>200$ \\
\hline Cauliflower DNA polymerase II ( $\beta$-like) & $>200$ \\
\hline \multicolumn{2}{|l|}{ Prokaryotic DNA polymerases } \\
\hline E. coli DNA polymerase I (Klenow fragment) & $>200$ \\
\hline Taq DNA polymerase & $>200$ \\
\hline T4 DNA polymerase & $>200$ \\
\hline \multicolumn{2}{|l|}{ Other DNA metabolic enzymes } \\
\hline Calf primase of DNA polymerase $\alpha$ & $>200$ \\
\hline T7 RNA polymerase & $>200$ \\
\hline Human DNA topoisomerase I & $5.0 \pm 1.5$ \\
\hline Human DNA topoisomerase II & $7.5 \pm 2.0$ \\
\hline T4 polynucleotide kinase & $>200$ \\
\hline Bovine deoxyribonuclease I & $>200$ \\
\hline
\end{tabular}

Compound 5 was incubated with each enzyme. Enzymatic activity in the absence of the compound was taken as $100 \%$. Data are shown as the means \pm SEM of four independent experiments.

of the -OH group, respectively. The other compounds are markedly different from compounds 5 and 6 . These results suggested that the three-dimensional position of hydrophobicity, such as the hydroxyl group, was essential for the inhibitory activities of pols, topos and cancer cell growth.

\section{Effects of compounds 5 on DNA metabolic enzymes}

Since compound 5 had the strongest bioactivity of the acetogenins investigated, this review focuses on compound 5 in the latter part. As shown in Table II, this compound inhibited the activities of the mammalian pols tested with $\mathrm{IC}_{50}$ values of 2.3-15.8 $\mu \mathrm{M}$. The pol $\lambda$ inhibitory effect of compound 5 was the strongest in mammalian pols. Furthermore, this compound inhibited animal pols from fish (cherry salmon) pol $\delta$, and insect (fruit fly) pols $\alpha, \delta$ and $\varepsilon$ at almost the same concentration as the inhibition of mammalian pols. On the other hand, compound 5 did not significantly influence the activities of pols I ( $\alpha$-like pol) and II ( $\beta$-like pol) from plants (cauliflower) and prokaryotes such as the Klenow fragment of E. coli pol I, Taq pol and T4 pol.

In the DNA metabolic enzymes tested, compound 5 also inhibited the activities of human topos I and II with $\mathrm{IC}_{50}$ values of 5.0 and $7.5 \mu \mathrm{M}$, respectively (Table II). This compound did not inhibit the activities of the other DNA metabolic enzymes tested, including calf primase of pol $\alpha$, T7 RNA polymerase, T4 polynucleotide kinase and bovine deoxyribonuclease I.

To determine whether the inhibitor resulted in binding to DNA or the enzyme, the interaction of compound 5 with double-stranded DNA (dsDNA) was investigated based on the thermal transition of dsDNA with or without the compound. The melting temperature of dsDNA with an excess amount of compound $5(100 \mu \mathrm{M})$ was measured using a spectrophotometer equipped with a thermoelectric cell holder. In the concentration range used, no thermal transition of the melting temperature was observed. In contrast, when ethidium bromide, a typical intercalating compound, was used as a positive control a clear thermal transition was produced. These observations indicated that compound 5 did not intercalate to DNA as a template-primer; thus, the compound directly binds to the enzyme and inhibits its activity.

These results suggested that compound 5 is a potent and selective inhibitor of animal pols and human topos. Consequently, the mechanism of the inhibitory effect of compound 5 on human cancer cells was investigated.

\section{Effects of compound 5 on cultured human cancer cells}

The growth suppression specificity of human cancer cell species by compound 5 was investigated (Table III). This compound inhibited the growth of the cancer cell lines tested, and the range of $\mathrm{IC}_{50}$ values was 9.4-16.1 $\mu \mathrm{M}$. The inhibitory effect on non-adherent cell lines, such as BALL-1 and HL-60, was approximately 1.5 -fold stronger than that on other adhering cell lines. The inhibitory effect of the 48-h culture was as strong as that of the $24-h$ incubation. The $\mathrm{LD}_{50}$ values of compound 5 for cancer cell growth were almost the same as the $\mathrm{IC}_{50}$ values for pols and topos. Therefore, this compound may penetrate cancer cells and reach the nucleus, inhibiting the activities of pols and topos. Moreover, the inhibition of enzyme activities by compound 5 may lead to cell growth suppression. Since compound 5 was the strongest cell growth inhibitor of HL-60 in the human cancer cell lines tested, this cell line was examined in the latter part of this review.

\section{Effects of the influence on HL-60 cells by compound 5}

The cell cycle distribution of compound 5-treated HL-60 cells was investigated. As shown in Fig. 4, the cell cycle fraction was recorded after 12 and $24 \mathrm{~h}$ of treatment with the $\mathrm{LD}_{50}$ value of the compound (i.e., $9.4 \mu \mathrm{M}$ ). Consequently, among cells treated with compound 5 for $12 \mathrm{~h}$, the population of cells in the $\mathrm{G} 2 / \mathrm{M}$ phase increased (9.6-15.2\%), the percentage of 
Table III. $\mathrm{LD}_{50}$ values of compound 5 on the growth of human cancer cell lines.

\begin{tabular}{llr}
\hline Species of human cells & \multicolumn{1}{c}{ Type of cancer } & LD $_{50}$ values $(\mu \mathrm{M})$ \\
\hline A549 & Lung cancer & $15.2 \pm 1.3$ \\
BALL-1 & B cell acute lymphoblastoid leukemia & $9.9 \pm 0.9$ \\
HCT116 & Colon carcinoma cancer & $14.8 \pm 1.2$ \\
HeLa & Cervix cancer & $16.1 \pm 1.4$ \\
HL-60 & Promyelocytic leukemia & $9.4 \pm 0.8$ \\
NUGC-3 & Stomach cancer & $15.6 \pm 1.3$
\end{tabular}

Human cancer cell lines were incubated with these compounds for $24 \mathrm{~h}$. Cell viability was determined by MTT assay (29). The results were calculated as the percentage of values obtained with untreated cells, and data are shown as the means \pm SEM of five independent experiments.

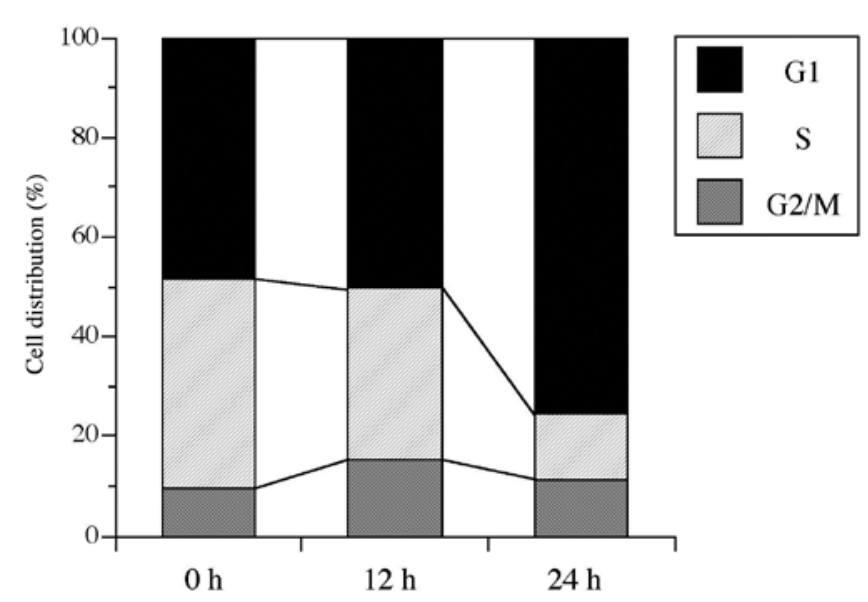

Figure 4. Effect of compound 5 on the cell cycle. HL-60 cells were incubated without (control) or with $9.4 \mu \mathrm{M}$ compound 5 for 0,12 and $24 \mathrm{~h}$. Cell cycle distribution was calculated as the percentage of cells in G1, S and G2/M phases. Experiments were performed three times.

cells in the S phase decreased from 42.1 to $34.5 \%$, and the G1 phase was not affected. These results suggested that the actions of this compound blocked the G2/M phase in HL-60 cells. Following $24 \mathrm{~h}$ treatment of compound 5, the cell population in the G1 phase significantly increased from 48.3 to $75.6 \%$, but the $\mathrm{S}$ phase decreased (42.1-13.1\%). Dehydroaltenusin, a specific pol $\alpha$ inhibitor, inhibited the cell cycle in the G1 phase, including the early S phase (30), while classical topo inhibitors, such as etoposide, arrested the cell cycle at the $\mathrm{G} 2 / \mathrm{M}$ phase (31). Therefore, compound 5 is more effective in the inhibition of pols than topos in the 24-h cell incubation, although compound 5 inhibited the activities of mammalian pols and human topos, and the inhibitory effect on topos $\left(\mathrm{IC}_{50}\right.$ values 5.0-7.5 $\mu \mathrm{M})$ was almost the same as that for pols $\left(\mathrm{IC}_{50}\right.$ values 2.3-15.8 $\mu \mathrm{M}$ ) in vitro (Table II).

To examine whether the decrease in cell numbers caused by compound 5 was due to apoptosis, DNA fragmentation was analyzed by electrophoresis. DNA ladder formation was dose-dependently observed in HL-60 cells treated with the $\mathrm{LD}_{50}$ value of the compound (i.e., $9.4 \mu \mathrm{M}$ ), and ladders were apparent at $3 \mathrm{~h}$ (Fig. 5). These results suggested that apoptotic effects were evident in the cells, and the effect of the

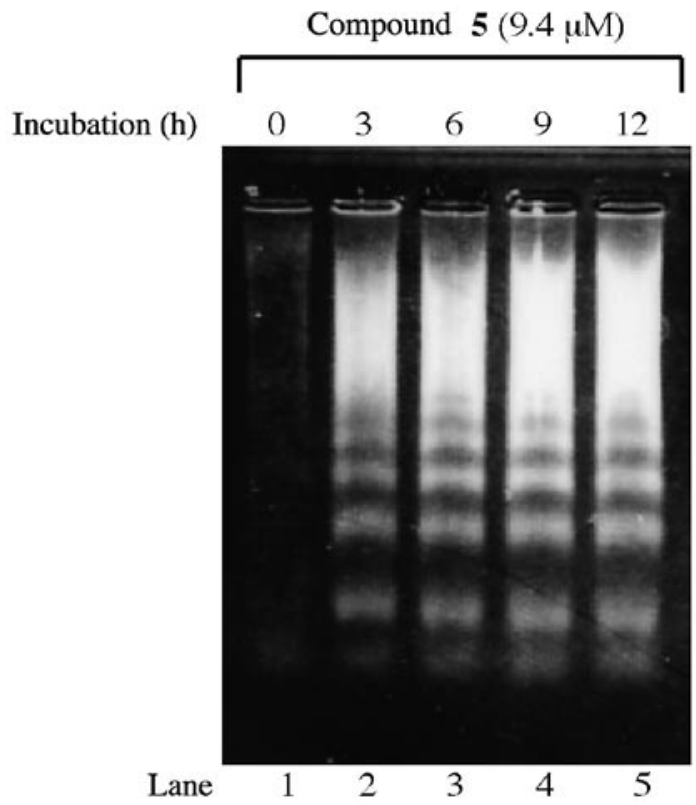

Figure 5. Detection of intracellular DNA ladder formation in HL-60 cells treated with $9.4 \mu \mathrm{M}$ compound 5. HL-60 cells treated with $9.4 \mu \mathrm{M}$ compound 5 for $0 \mathrm{~h}$ (lane 1), $3 \mathrm{~h}$ (lane 2), $6 \mathrm{~h}$ (lane 3), $9 \mathrm{~h}$ (lane 4) and $12 \mathrm{~h}$ (lane 5). Following cell lysis, total DNA was extracted and analyzed by $1.4 \%$ agarose gel electrophoresis. DNA bands were stained with ethidium bromide and visualized under UV light.

compound must involve a combination of growth arrest and cell death.

\section{Discussion}

Most acetogenins exhibit potent and selective in vitro anti-tumor activities. For example, compound 1 (mucocin) reportedly shows significant inhibitory activities against A-549 (lung cancer) and PACA-2 (pancreatic cancer) solid tumor lines (32). As the main mode of action, blockage of the mitochondrial NADH-ubiquinone oxidoreductase in complex I, which is a membrane-bound and essential enzyme for ATP production, is discussed (32). Furthermore, these natural products were shown to inhibit a ubiquinone-linked NADH oxidase found in the plasma membrane of specific tumor 
cell lines, including some which show multidrug resistance (33). However, research on the inhibition of acetogenins against pol and topo activities is limited, probably due to the small quantities of natural products. Since the total synthesis of bioactive acetogenins, such as compound 5, is possible (17-25), these compounds should be provided and studied in pharmaceutical research throughout the world.

Compound 5 directly inhibited animal pol and human topo activities (Table II), but did not bind to DNA. These observations suggested some structural similarity between the enzymes at the compound 5 binding site, although the characteristics of pols and topos, including their modes of action, amino acid sequences and three-dimensional structures, are markedly different. We previously reported that several inhibitors, long-chain fatty acids $(26,27)$ and triterpenoids $(34,35)$ of mammalian pol $\beta$ also inhibited topo II activity. The two enzymes had a structural homology at the DNA-binding site (36-38). Moreover, the DNA-binding site of long-chain fatty acids on the pol was the same domain (i.e., N-terminal 8-kDa domain of pol $\beta$ ) as that of triterpenoids $(36,39)$; therefore, compound 5 was expected to have similar characteristics. Pols and topos have recently emerged as important cellular targets for chemical intervention in the development of anti-cancer agents. Therefore, information concerning the structural characteristics of these inhibitors may provide valuable insight for the design of new anticancer agents.

In acetogenins, the molecular length and width, as well as the surface area of the neighboring negative and positive charges are regarded as important for mammalian pol inhibition, human topo inhibition and human cancer cell cytotoxicity. Continuing computer simulation analyses, however, will result in more effective pol and topo inhibitors than compound 5.

\section{Conclusion}

Chemically synthesized acetogenins inhibited the activities of mammalian pols, human topos and human cancer cell growth. In particular, compound 5 (pyranicin) showed the strongest inhibition of the tested acetogenins, and it was revealed that the inhibition of pol and topo activities by compound 5 influenced not only cell proliferation but also the cell cycle and apoptosis induction. Therefore, compound 5 is the lead compound of potentially useful cancer chemotherapy agents.

\section{Acknowledgements}

This work was supported in part by a Grant-in-Aid for Kobe-Gakuin University Joint Research (A), and the 'Academic Frontier' Project for Private Universities: matching fund subsidy from the Ministry of Education, Science, Sports, and Culture of Japan (MEXT), 2006-2010, (H.Y. and Y.M.). Y.M. acknowledges a Grant-in-Aid for Young Scientists (A) (No. 19680031) from MEXT, Grantsin-Aid from the Nakashima Foundation (Japan), Foundation of Oil and Fat Industry Kaikan (Japan), The Salt Science Research Foundation, No. 08S3 (Japan), and a Grant from the Industrial Technology Research Program from NEDO (Japan).

\section{References}

1. Rupprecht JK, Hui YH and McLaughlin JL: Annonaceous acetogenins: a review. J Nat Prod 53: 237-278, 1990.

2. Alali FQ, Liu XX and McLaughlin JL: Annonaceous acetogenins: recent progress. J Nat Prod 62: 504-540, 1999.

3. Berrnejo A, Figadere B, Zafra-Polo MC, Barrachina I, Estornell E and Cortes D: Acetogenins from Annonaceae: recent progress in isolation, synthesis and mechanisms of action. Nat Prod Rep 22: 269-303, 2005.

4. Alali FQ, Rogers L, Zhang Y and McLaughlin JL: Unusual bioactive annonaceous acetogenins from Goniothalamus giganteus. Tetrahedron 54: 5833-5844, 1998.

5. Chavez D, Acevedo LA and Mata R: Jimenezin, a novel annonaceous acetogenin from the seeds of Rollinia mucosa containing adjacent tetrahydrofuran-tetrahydropyran ring system. J Nat Prod 61: 419-421, 1998

6. Shi G, Alfonso D, Fatope MO, Zeng L, Gu ZM, Zhao GX, He K, MacDougal JM and McLaughlin JL: Mucocin: a new annonaceous acetogenin bearing a tetrahydropyran ring. J Am Chem Soc 117: 10409-10410, 1995.

7. Shi G, Kozlowski JF, Schwedler JT, Wood KV, MacDougal $\mathrm{JM}$ and McLaughlin JL: Muconin and mucoxin: additional nonclassical bioactive acetogenins from Rollinia mисоsa. J Org Chem 61: 7988-7989, 1996.

8. Kornberg A and Baker TA: Eukaryotic DNA polymerase. In: DNA replication. 2nd edition. Freeman WH and Co., New York, pp197-225, 1992.

9. Hubscher U, Maga G and Spadari S: Eukaryotic DNA polymerases. Annu Rev Biochem 71: 133-163, 2002.

10. Bebenek $K$ and Kunkel TA: DNA repair and replication. In: Advances in Protein Chemistry. Vol 69. Yang W (ed.) Elsevier, San Diego, pp137-165, 2004.

11. Takata K, Shimizu T, Iwai S and Wood RD: Human DNA polymerase $\mathrm{N}$ (POLN) is a low fidelity enzyme capable of error-free bypass of 5S-thymine glycol. J Biol Chem 281: 2344523455, 2006.

12. Wang JC: DNA topoisomerases. Annu Rev Biochem 65: 635-692, 1996.

13. Chakraborty AK and Majumder HK: Mode of action of pentavalent antimonials: specific inhibition of type I DNA topoisomerase of Leishmania donovani. Biochem Biophys Res Commun 152: 605-611, 1988.

14. Liu LF: DNA topoisomerase poisons as antitumor drugs. Annu Rev Biochem 58: 351-375, 1989.

15. Ray S, Hazra B, Mittra B, Das A and Majumder HK: Diospyrin, a bisnaphthoquinone: a novel inhibitor of type I DNA topoisomerase of Leishmania donovani. Mol Pharmacol 54: 994-999, 1998.

16. Sakaguchi K, Sugawara F and Mizushina Y: Inhibitors of eukaryotic DNA polymerases. Seikagaku 74: 244-251, 2002.

17. Pupo MT, Vieira PC, Fernandes JB and da Silva MFGF: $\gamma$-Lactones from Trichilia claussenii. Phytochemistry 48: 307-310, 1998.

18. Takahashi $\mathrm{S}$ and Nakata T: Total synthesis of an antitumor agent, mucocin, based on the 'chiron approach'. J Org Chem 67: 5739-5752, 2000.

19. Takahashi S, Kubota A and Nakata T: Stereoselective total synthesis of mucocin, an antitumor agent. Angew Chem Int Ed Engl 41: 4751-4754, 2002.

20. Takahashi S, Maeda K, Hirota S and Nakata T: Total synthesis of a new cytotoxic acetogenin, jimenezin, and the revised structure. Org Lett 1: 2025-2028, 1999.

21. Takahashi S, Kubota A and Nakata T: Stereoselective total synthesis of muconin. Tetrahedron 59: 1627-1638, 2003.

22. Takahashi S, Kubota A and Nakata T: Total synthesis of a cytotoxic acetogenin, pyranicin. Org Lett 5: 1353-1356, 2003.

23. Takahashi S, Ogawa N, Koshino H and Nakata T: Total synthesis of the proposed structure for pyragonicin. Org Lett 7: 2783-2786, 2005.

24. Takahashi S, Hongo H, Ogawa N, Koshino H and Nakata T: Convergent synthesis of pyragonicin. J Org Chem 71: 6305-6308, 2006.

25. Takahashi S, Ogawa N, Sakairi N and Nakata T: Stereoselective synthesis of (2R,3S,4S)-3-hydroxy-4-methyl-2-tetradecyl-4butanolide starting from 2,5-anhydro-D-mannitol. Tetrahedron 61: 6540-6545, 2005.

26. Mizushina Y, Tanaka N, Yagi H, Kurosawa T, Onoue M, Seto H, Horie T, Aoyagi N, Yamaoka M, Matsukage A, Yoshida S and Sakaguchi K: Fatty acids selectively inhibit eukaryotic DNA polymerase activities in vitro. Biochim Biophys Acta 1308: 256-262, 1996. 
27. Mizushina Y, Yoshida S, Matsukage A and Sakaguchi K: The inhibitory action of fatty acids on DNA polymerase $\beta$. Biochim Biophys Acta 1336: 509-521, 1997.

28. Ishimaru C, Yonezawa Y, Kuriyama I, Nishida M, Yoshida H and Mizushina Y: Inhibitory effects of cholesterol derivatives on DNA polymerase and topoisomerase activities, and human cancer cell growth. Lipids 43: 373-382, 2008.

29. Mosmann T: Rapid colorimetric assay for cellular growth and survival: application to proliferation and cytotoxicity assays. J Immunol Methods 65: 55-63, 1983.

30. Murakami-Nakai C, Maeda N, Yonezawa Y, Kuriyama I, Kamisuki S, Takahashi S, Sugawara F, Yoshida H, Sakaguchi $\mathrm{K}$ and Mizushina Y: The effects of dehydroaltenusin, a novel mammalian DNA polymerase $\alpha$ inhibitor, on cell proliferation and cell cycle progression. Biochim Biophys Acta 1674: 193-199, 2004.

31. Nishida K, Seto M and Ishida R: Different susceptibilities of postmitotic checkpoint-proficient and -deficient Balb/3T3 cells to ICRF-193, a catalytic inhibitor of DNA topoisomerase II. Jpn J Cancer Res 92: 193-202, 2001.

32. Degli Esposti M: Inhibitors of NADH-ubiquinone reductase: an overview. Biochim Biophys Acta 1364: 222-235, 1998.

33. Oberlies NH, Chang CJ and McLaughlin JL: Structure-activity relationships of diverse Annonaceous acetogenins against multidrug resistant human mammary adenocarcinoma (MCF-7/ Adr) cells. J Med Chem 40: 2102-2106, 1997.
34. Mizushina Y, Tanaka N, Kitamura A, Tamai K, Ikeda M, Takemura M, Sugawara F, Arai T, Matsukage A, Yoshida S and Sakaguchi K: The inhibitory effect of novel triterpenoid compounds, fomitellic acids, on DNA polymerase $\beta$. Biochem J 330: 1325-1332, 1998.

35. Tanaka N, Kitamura A, Mizushina Y, Sugawara F and Sakaguchi K: Fomitellic acids, triterpenoid inhibitors of eukaryotic DNA polymerases from a basidiomycete, Fomitella fraxinea. J Nat Prod 61: 193-197, 1998.

36. Mizushina Y, Ohkubo T, Date T, Yamaguchi T, Saneyoshi M, Sugawara F and Sakaguchi K: Mode analysis of a fatty acid molecule binding to the N-terminal $8-\mathrm{kDa}$ domain of DNA polymerase $\beta$. J Biol Chem 274: 25599-25607, 1999.

37. Mizushina Y, Sugawara F, Iida A and Sakaguchi K: Structural homology between DNA binding sites of DNA polymerase $\beta$ and DNA topoisomerase II. J Mol Biol 304: 385-395, 2000.

38. Mizushina Y, Iida A, Ohta K, Sugawara F and Sakaguchi K: Novel triterpenoids inhibit both DNA polymerase and DNA topoisomerase. Biochem J 350: 757-763, 2000.

39. Mizushina Y, Ohkubo T, Sugawara F and Sakaguchi K: Structure of lithocholic acid binding to the N-terminal $8-\mathrm{kDa}$ domain of DNA polymerase $\beta$. Biochemistry 39: 12606-12613, 2000. 